\title{
“CIPRÉS, EL TRIUNFADOR”. EL BOSQUE ANDINO PATAGÓNICO, LA CIENCIA, LA MORAL Y LA SALUD SOCIAL EN ARGENTINA ENTRE FINES DEL SIGLO XIX Y LA DÉCADA DEL '30
}

\author{
Paula Gabriela Núñez \\ Universidad de Los Lagos / Instituto de Investigación en Diversidad Cultural y Procesos de Cambio (IIDYPCA), \\ Universidad Nacional de Río Negro-CONICET \\ pnunez@unrn.edu.ar \\ http://orcid.org/0000-0002-2008-2643
}

Carolina Lema

Instituto de Investigación en Diversidad Cultural y Procesos de Cambio (IIDYPCA), Universidad Nacional de Río Negro-CONICET carolina.lema2@gmail.com http://orcid.org/0000-0001-7435-3739

Recibido: 16 junio 2017; Aceptado 16 julio 2018.

Cómo citar este artículo/Citation: Núñez, Paula Gabriela (2019), Carolina Lema, “' 'Ciprés, el triunfador'. El bosque andino patagónico, la ciencia, la moral y la salud social en Argentina entre fines del siglo XIX y la década del '30", Asclepio, 71 (1): p258. https:// doi.org/10.3989/asclepio.2019.10.

RESUMEN: Este trabajo, inscripto en la historia de las ciencias, recorre cómo, en el reconocimiento científico del bosque andino patagónico argentino, se introducen valoraciones que ubican al mismo como parte de la salud social, que redunda en la jerarquización asimétrica de la población. Se revisan los escritos de los primeros naturalistas que, desde fines del siglo XIX, observan el espacio, y se avanza tomando estudios hasta entrada la década del '30. El recorte temporal se extiende hasta el establecimiento de políticas de conservación, a partir de la creación del Parque Nacional Nahuel Huapi, en 1934. La mirada sobre la ciencia indaga en las tradiciones de estudio de los diferentes grupos de especialistas que escriben sobre el espacio, y el modo en que estas investigaciones dialogan con políticas concretas de apropiación e intervención, que no se circunscriben a las prácticas internas de la biología de estos años, sino que se encuentran atravesadas por las concepciones organicistas desde las cuales se diseña la salud social. A lo largo de estas páginas se caracterizan las tradiciones de investigación en biología y se encuentra que las políticas trasladan, desde la mirada sobre la salud, los principios de conservación y uso social del bosque.

PALABRAS CLAVE: naturaleza; Patagonia andina; tradiciones científicas; organicismo; salud social.

"CIPRES, THE TRIUMPHANT". THE ANDEAN PATAGONIAN FOREST, THE SCIENCE, THE MORAL AND THE SOCIAL HEALTH IN ARGENTINA BETWEEN LATE XIXTH CENTURY AND THE '3OS DECADE

ABSTRACT: This paper, as part of history of science, researches how the scientific recognition of Andean Patagonian Forest introduces values that located the forest as part of social health, and that implied the asymmetric hierarchy of the population. It reviews the writings of the first naturalists who study the countryside since the end of the 19th Century, and It continues taking into account studies until the late 1930's. The temporal cut covers until the establishment of conservation policies, starting with the creation of the Nahuel Huapi National Park in 1934. The analytical perspective over the science inquires into the study traditions of the different groups of specialists who write about space, and the forms that these researches were in dialogue with appropriation and intervention policies, which are not confined into the internal practices of the biology of these years, but are crossed by the organicist conceptions from which social health is designed. Along these pages the biological research traditions are characterized and it evidences that policies transfer, from social health conceptions, the principles of conservation and social use of the forest.

KEY WORDS: nature; Andean Patagonia; scientific traditions; organicism; social health.

Copyright: (C) 2019 CSIC. Este es un artículo de acceso abierto distribuido bajo los términos de la licencia de uso y distribución Creative Commons Reconocimiento 4.0 Internacional (CC BY 4.0). 


\section{INTRODUCCIÓN}

En este escrito indagamos el reconocimiento científico de la flora andina patagónica para de allí trazar cómo, en la manera en que se la define, se introduce una compleja matriz valorativa que va a redundar en la legitimación de determinados órdenes sociales, que se interpretan como parte de esa "naturaleza", que es tomada como fija. El reconocimiento de este paradójico interjuego lleva a revisar los fundamentos de las descripciones científicas relativas a la región andina de la Patagonia argentina, elaboradas desde la apropiación territorial de la misma, a fines del siglo XIX, hasta la efectiva instalación de los Parques Nacionales como políticas nacionales ${ }^{1}$. En este proceso se evidencian como intervienen las perspectivas organicistas que atraviesan la política social del período (Vallejo y Miranda, 2014).

La relevancia del tema descansa en el carácter paradojal del reconocimiento de lo natural. Pues vista en el tiempo, esa "naturaleza" fija, que opera como una suerte de "autoridad moral" para marcar los estándares de lo que resulta correcto (Daston y Vidal, 2004), es interpretada de forma cambiante. Dentro del análisis sobre el sentido del bosque andino patagónico argentino, una extensa bibliografía ha dado cuenta de su rol como frontera (Nouaeillez, 1999; Bessera, 2008; Klubock, 2014), a ello se agregan justificaciones a disciplinamientos clasistas (Méndez y Podlubne, 2008), e incluso de derechos obreros (Núñez, 2015) o redes comerciales (Méndez y Muñoz, 2013). En todos los casos se remite a referencias que inscriben, en el paisaje, la fijeza de cada una de esas definiciones mencionando el porqué ese paisaje debe cuidarse, en una retórica que ligó los bosques a valoraciones nacionalistas, que en la "belleza primigenia" encontraban fundamento para el orden político establecido (Sanz Lafuente, 2003).

El discurso científico sobre la Patagonia ha sido revisado por Navarro Floria $(2004,2007)$ evidenciando un conocimiento que, junto a las observaciones, suponía al orden estatal y al utilitarismo como parte del paisaje. Similarmente, en Brasil, Horta Duarte (2014) encuentra, entre las décadas del '30 y '40, que la construcción de conocimiento biológico se liga a la emergencia del nacionalismo. Diegues (2005) evidenció la necesidad de los Estados latinoamericanos por establecer espacios prístinos como referencia patriótica, lo cual lleva a que la pregunta por el sentido de la foresta cobre una particular complejidad en este continente. Esta reflexión dialoga con la pregunta por el bosque como referencia moral (Nouaeillez, 1999; Sanz Lafuente, 2003; Daston y Vidal, 2004), que desde numerosos estudios indica la relevancia de vincular la caracterización del bosque desde la botánica y la ciencia forestal, con el ordenamiento social que se delinea como natural para el territorio (FritzVietta, 2016; Werry, 2008) y que en el caso que nos ocupa ha sido escasamente analizado.

\section{LA APRopiación CIENTífica de la PATAgonia}

Los relatos científicos sobre la Patagonia están cruzados por su integración territorial tardía, resuelta a fines del siglo XIX, cuando las formas institucionales del país estaban definidas configurando discursos que ubicaron esta región en un sitio de subalternidad (Navarro Floria, 2004, 2007; Bandieri, 2015). Este proceso de incorporación ha sido estudiado desde perspectivas que permiten reconocer que la integración efectiva de la región al Estado argentino se logró aproximadamente en la década del '30, a través de la creación de instituciones específicas (luorno y Crespo, 2008), pues en períodos previos la articulación se resolvía en buena medida a través de los lazos sociales que ligaban el sur argentino con el chileno (Carrizo, 2007; Coronato, 2010; Méndez y Muñoz, 2013). Esta particularidad dio lugar a consideraciones específicas sobre la población en este espacio que dialogaron con la mirada científica sobre el territorio.

Si bien la apropiación estatal de la Patagonia suele describirse como militar, además fue fuertemente académica. De hecho, es en una publicación de carácter científico donde se configura la pertenencia de la Patagonia a la República Argentina. Allí aparece además uno de los primeros discursos naturalistas específicamente relacionado a la comprensión del bosque que se revisará.

El texto de Napp "La República Argentina”, editado en $1876^{2}$, es la primera obra técnica que refiere a la Patagonia como espacio de conocimiento. Esta obra tenía como objetivo presentar la Argentina al mundo. La Patagonia se dibuja como parte del país, aún cuando en el mismo texto se reconozca el desconocimiento total sobre el territorio. La discusión sobre la pertenencia nacional de la Patagonia es un argumento central del texto, no tanto por la efectiva apropiación, que de hecho se explicita como no resuelta, sino por 
la herencia colonial a la que se refiere como argumento del conflicto de límites que comienza a plantearse con Chile, en relación a los valles cordilleranos ${ }^{3}$.

Esta obra introduce el mapa de la Patagonia en línea con lo que Lois (2006) define como "deseo territorial". Esto es, una descripción que apela a lo físico como fundamento de una política que busca establecerse. Inscribe la materialidad, que no se ha llegado a observar, como evidencia de un desarrollo planificado como natural.

En el texto de Napp, la Patagonia se presenta en el capítulo XXIII, como parte de un compendio titulado "Indios y Fronteras"4. En este apartado se distingue a los "Indios de la Patagonia" y a los "Indios del Gran Chaco", además de una sección titulada "Explicaciones sobre el mapa de la Pampa que acompaña este libro", donde la Patagonia se describe como inexplorada en términos de datos confiables.

Si observamos la Figura 1, notamos que, además de la delimitación patagónica, como resuelta a pesar del conflicto con Chile, los límites del norte son difusos.
La representación cartográfica de un territorio presentado como desconocido lleva a la pregunta por la producción de conocimiento sobre el mismo. Transformado el deseo territorial en representación espacial, y alistadas las fuerzas estatales a concretar el proyecto, una comisión científica acompañó la avanzada militar como forma de anclar la apropiación en la ciencia. La misma estuvo conformada por los botánicos Lorentz y Niederlein y los zoólogos y geólogos Döring y Schulz. Todos alemanes emigrados a Argentina. Durante tres meses de 1879 se dedicaron a acompañaron a las tropas del General Julio Argentino Roca, recogiendo, identificando y categorizando todo tipo de plantas, animales y minerales. El resultado fueron tres libros publicados entre 1881 y 1884, Zoología (1881), Botánica (1883), Geología (1884) y el Diario de los miembros de la Comisión Científica de la expedición de 1879, publicado en 1916. En la obra el territorio a incorporar se presenta como un desierto transformable, donde se encuentran el peligro de un orden imposible para el desarrollo, junto al futuro promisorio, pues los recursos patagónicos serían la base para la grandeza del país.

FIGURA 1: Mapa de Argentina 1876 y actual
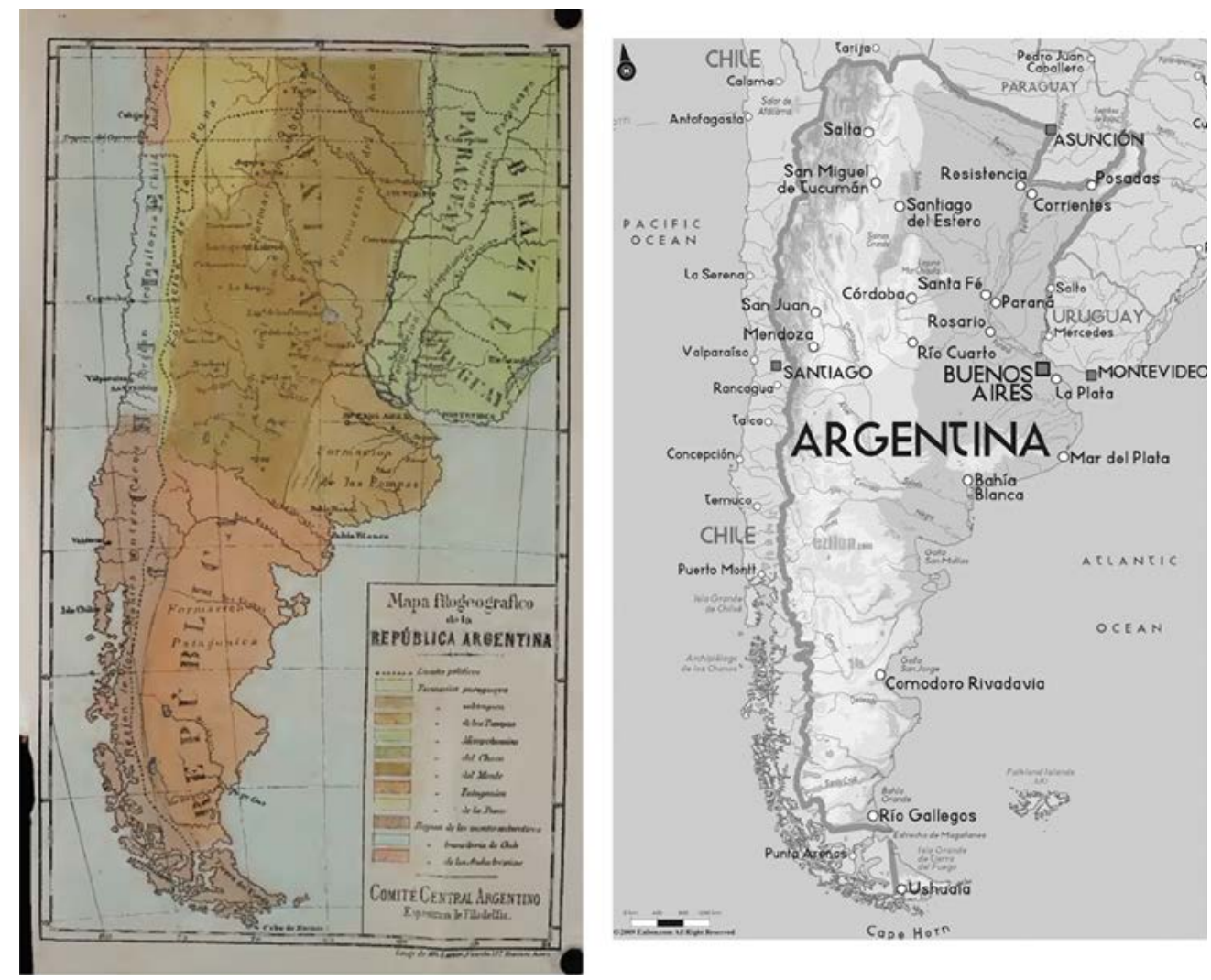

Napp, 1876, sin paginado y https://www.recope.go.cr/noviembre-11-2015/mapa-de-argentina/ [visto 28 de febrero de 2018]. 
Una de las principales obras de promoción de esa conquista fue el texto de Zeballos ${ }^{5}$ de $1878^{6}$, que es particularmente elocuente en relación a zona andina. $Y$ ello es relevante por el enorme impacto de este escrito en su época, que casi se agota al momento de su publicación, además de la relevancia de su autor en el armado de la red científica en Argentina. En relación a los Andes patagónicos indica "El Dr. Lorentz, que ha publicado obras importantes sobre la Flora Argentina... dice que el pie de las cordilleras y el de sus ramificaciones orientales está rodeado en una extensión de varias leguas por una zona rica y espléndida. Aquel escritor encuentra allí el Edén de la República Argentina, porque la suavidad y majestad de la naturaleza se hermanan a una feracidad admirable, que ha sorprendido a los amantes de la botánica, ofreciéndoles un nuevo e inagotable teatro de investigación científica" (Zeballos, 1878, p. 204).

Zeballos cita como literal el texto que Lorentz escribe dentro del libro que Napp compiló ${ }^{7}$, pero omite decir que esta descripción refiere a las exploraciones del norte del territorio argentino, donde la vegetación es descripta como "formación subtropical" (Lorentz, 1876, p. 79), dos palabras que Zeballos se ocupa de borrar. Para Lorentz, la Patagonia es casi desconocida en 1876. Lorentz, de hecho dedica algunas páginas a la "formación del bosque antártico" (pp. 82-83) y "formación patagónica" (pp. 83-85), donde el bosque se circunscribe al primer título, y donde la caracterización de las especies se da desde lo observado en la falda occidental de la cordillera, en Chile. Sobre la falda oriental solo hay observaciones parciales y supuestos que terminan con la siguiente reflexión" ... á la pregunta de si los bosques de Hayas de las faldas patagónicas é internas de las Cordilleras no podrían ser explotadas por una población enérgica y laboriosa, no sería posible responder negativamente, tanto menos cuanto que en las riberas del alto Rio Negro se encuentran - según se dice - bosques de pinos y de manzanos silvestres, que constituyen, tanto aquí como en las faldas chilenas, el paraíso de los Indios...No conozco descripción alguna buena y detallada de estas comarcas...Mientras el Patagón salvaje lleve una vida errante en las llanuras de su pátria, no entrará la civilización en aquellos bosques primitivos" (p. 83). La ciencia natural legitimaba la mirada estatal que argumentaba a favor de un cambio poblacional, era parte de la retórica central para el cambio de la sociedad (Horta Duarte, 2010).

La descripción botánica refiere a un resultado que proyecta la organización del territorio, antes que el detalle de la flora. Las plantas se exponen desde su uso deseado. El saber científico describe un territorio no tanto desde sus características físicas, sino desde sus adscripciones económico-políticas, pues se habla de un espacio que es argentino, que no saldrá de un estado primitivo si no se cambia la población y que representa al país como promesa de progreso. La argentinización, en esta clave racista y capitalista, resulta previa y marca el conocimiento de la región ${ }^{8}$. El desconocido territorio patagónico cordillerano es especialmente marcado. Tanto en el citado libro de Napp (1876) como en Moreno (1902) $)^{9}$ donde se presentan los argumentos argentinos frente a la Comisión Arbitral convocada por ambos países para dirimir este litigio. Los mapas trazan con particular detalle el espacio patagónico, pero el territorio del norte queda en un sitio ambiguo, sin que ello signifique, de hecho, un contrapunto internacional de la dimensión del ordenamiento patagónico pues en el norte del país, los límites están resueltos para la fecha del segundo. No se inscribe en el papel la negociación ya resuelta, mientras que en el sur se cartografía como resuelto el límite, justo allí donde el espacio tiene un conflicto abierto.

\section{LA DESCRIPCIÓn CIENTífiCA de la Patagonia}

La década de 1870 parecería ser la de la pregunta por la Patagonia. Las primeras observaciones científicas reconocidas, realizadas por Moreno desde 1873, se sintetizan en su "Viaje a la Patagonia Austral", editado en $1879^{10}$. En el prólogo del texto, haciendo alusión al conflicto de los límites patagónicos con Chile, señala "Discutimos hace tiempo las tierras australes sin conocerlas" (Moreno, 1879, p. VII) ${ }^{11}$. Moreno apela a que la incorporación del territorio pasa por el conocimiento del mismo, "En estos últimos años el interés particular ha esparcido noticias llenas de contradicciones, que abogan unas por la fertilidad y las inmensas riquezas que encierran... y otras en que se pinta con los colores más sombríos, como para hacer abandonar toda idea de utilizarlos. Hácese, pues, necesario que sepamos con seguridad, con qué elementos puede contribuir Patagonia á la prosperidad de la República y esto sólo se puede conseguir conociendo su geografía y sus condiciones naturales" (p. VII).

Sin conocer el territorio, se plantea un conocimiento al servicio del armado económico del país, ya propuesto en clave agroexportadora (Coronato, 2010). 
Es un lugar común de la historiografía patagónica reconocer que el discurso científico sobre el espacio apeló a una retórica utilitaria (Navarro Floria, 2004). Esto lleva a interpelar los puentes concretos que permiten de la ciencia a la política y viceversa. La ciencia vincula "territorio" y "población", en una mirada cargada del racismo propio del auge decimonónico de la antropología física Vallejo y Miranda (2004) inscriben la formación de las naciones americanas dentro de un marco organicista estructural. Señalan que el pensamiento argentino, de fines del siglo XIX, estuvo atravesado por una variante lamarckiana del darwinismo social, donde el ambiente aparece como determinante de las características de los habitantes. Por ello la idea de la naturaleza salvaje como imagen de la población incorrecta no se reduce a la población originaria. Esa idea se re-proyecta en la población migrante. La irracionalidad y barbarie reconocida en la aridez continuó siendo, a los ojos del Estado nacional, un límite para el ejercicio de la ciudadanía completa, negando a los pobladores del desierto como actores económicos racionales. Se observa una inestabilidad estructural que lleva al diseño de formas específicas de control ${ }^{12}$.

Por otro lado, mientras las áreas de intervención productiva se ven cambiantes, el bosque, y los sistemas considerados naturales, se presumen estables. Ello se consolida como programa de investigación ya entrado el siglo $\mathrm{XX}$, cuando se planteó la existencia de un clímax que no se modifica, ni en millones de años, a menos que se cruce con una catástrofe, El darwinismo da cuenta de los procesos evolutivos que llegan hasta la materialización de ese orden natural, en donde el cambio se detiene (Deléage, 1993). El ideólogo de la "teoría del Clímax" fue Clements ${ }^{13}$, uno de los botánicos y ecólogos más relevantes de su época, quien sostenía que cada región tiene sólo una comunidad clímax, hacia la cual las diferentes comunidades se desarrollan. Esta propuesta buscaba responder interrogantes que salen de la descripción de los organismos para instalarse en el de las relaciones y dinamismos. Sin embargo, apelaba a una explicación con arraigos teleológicos, pues, se apoyaba en elementos esencialistas como modo de discutir hacia nuevas perspectivas, y como forma de integrar las teorías que estaban tensionando la biología. Pero hay algo más en relación a que sea Clements quien propone el primer dinamismo general en relación al ordenamiento de especies. En estos años el orden botánico se presupone determinante sobre todo el resto de los órdenes (Martínez Alier, 1993; Deléage, 1993;
Sanz Lafuente, 2003), de allí que como se interprete la flora se interpreta "lo natural", pues la flora se presume síntesis de lo que es el territorio, y entonces marca lo que debe existir. Así el reconocimiento del bosque tiene, por la propia lógica del conocimiento biológico del período, relevancia de verdad.

\section{EL CAMBIO Y LA SALUD SOCIAL EN ARGENTINA}

Como "lo natural" no cambia, el control por llegar a lo natural se enmarca en las ideas biológicas que dan cuenta del cambio, que son las agrícolas, pero sobre todo, las de la salud si pensamos en términos de cambios poblacionales. Es en estas últimas donde se inscribe la dinámica para que algo devenga en su propia naturaleza, y no en lo agrícola, donde el cambio es un fin en sí mismo.

El modo de pensar la salud, y la forma en que el Estado adopta una perspectiva organicista, son centrales para entender el cambio sin cambios, como en el bosque o la población. Vallejo (2004) historiza el organicismo argentino desde las diferentes formas que va adoptando la eugenesia. Así marca un cambio en la concepción de salud social a partir de la biotipología desarrollada por Pende ${ }^{14}$ como mecanismo reconocido en la década del '20, e instalado en la del '30, que operó como control médico de la población, y que permite inferir dinámicas sobre cómo el reconocimiento de la población -humana- se trasladan al espacio y al paisaje.

Vallejo (2004) señala que la biotipología tuvo particular impacto en Argentina “... que tenía su fundamento en la detección de anormalidades físicas, psíquicas y morales no visibles que anticipen la comisión de actos perturbadores el orden público... con la biotipología toda la población debía quedar bajo la atenta mirada de una ciencia concebida para identificar y aislar aquello que en última instancia podía poner en riesgo la gobernabilidad" (pp. 221-222). Vallejo y Miranda $(2014$, p. 3) describen este proceso como "fatalismo ambiental positivo", donde la mirada sobre el bosque refiere en forma directa al "ambiente sano" propiciado desde esta línea de pensamiento. Desde el tema que nos ocupa esto inscribe la creación de los Parques Nacionales en el sostenimiento de paisajes educadores y sanadores de la población (Fortunato, 2005; Diegues, 2005) en una política que ha sido reconocida en el mundo (Werry, 2008; Travers et al., 2015; Fritz-Vietta, 2016) y que en América La- 
tina ha dado lugar a modalidades alternativas, con particularidades en países que toman a la explotación forestal como eje de producción (Boyer, 2015; Diegues, 2005), pero sin perder de vista la carga nacionalista del particular reconocimiento estatal dado a la naturaleza monumental y a su rol "naturalizador" de dinámicas de concentración. A decir de Boyer (2015) para México, esto "interviene el complejo y mutable panorama rural, transformando el bosque en un paisaje politizado que ha dañado el ecosistema y ha acentuado la injusticia social" (p. XIV), en una reflexión que contiene aspectos asimilables a otros espacios del continente y que retornan la pregunta por la salud social que se promueve desde el bosque inscripto en esta trama de valores.

La biotipología que se consolida en Argentina, y que entendemos como articulada a la visión del bosque del sur y la política desarrollada en consecuencia, se presenta como una superación del pensamiento lombrosiano, que se apoyaba en lo estrictamente observable, para pasar de "la antropología física a la antropología endócrina... nacida para detectar alteraciones individuales de tipo hormonal y moral capaces de transmitirse a la esfera social".

Si revisamos los modos en que se describe la $\mathrm{Pa}$ tagonia, encontramos la anormalidad como descriptor, en el sentido de ser y contener a la barbarie, por ser desierto. En la Patagonia, la transformación se presentó como una necesidad, una suerte de "cura" del mal de la barbarie que afectaba espacio y población. En línea con Schiebinger (2004) encontramos un racismo ambiental, que en su anclaje a identidades locales establecidas desde la particular construcción de naturaleza, transforma en nacional lo extranjero y lo nativo en foráneo. Ahora bien, llama la atención el criterio de autoridad, y la representación de lo sano, porque además de las referencias agrícolas, que homologan todos los espacios argentinos a los escenarios de la pampa, el bosque es la particularidad patagónica que aparece como muestra y referencia de la posibilidad y necesidad de transformación.

Como toda referencia anclada en lo recortado como "naturaleza", la autoridad que se reconoce en el bosque opera de una forma "oscura y paradójica" (Daston y Vidal, 2004). El bosque patagónico se explicita como ejemplo de los recursos "dormidos" de esa Patagonia que necesitaba desarrollarse, y paisaje emblemático de la argentinidad deseable, que se desarrollaba en las ciudades pero se sanaba en las montañas (Diegues, 2005). El bosque no es sólo recurso de un orden eco- nómico que se naturaliza, es referencia estética de un orden social. En esta interpretación se alimenta la deshumanización y patologización de aquellos presentados como pobladores problemáticos.

\section{LAS TRADICIONES BIOLOGICISTAS EN LA CIENCIA LOCAL}

Hay dos tradiciones presentes en la producción de conocimiento biológico en los años que nos ocupan, la anglosajona (británica-norteamericana) y la germana. La tradición anglosajona, explícitamente utilitarista, tiene argumentos que no refieren a un orden moral propio del comportamiento privado, sino al derecho de modificar el entorno en función de la obtención de ganancia, asumiendo al capitalismo como motor y objetivo de todas las iniciativas. Zusman (2012) ha recorrido la influencia panamericanista en Argentina en la institucionalización del espacio como Territorios Nacionales, y en las ideas de conservación de los Parques Nacionales, detallando como esta mirada deviene en política pública. Como síntesis del pensamiento científico del período sobre este espacio, Anasagasti et al., en $1926^{15}$, refieren directamente al modelo norteamericano en el diseño del primer Parque que se intenta establecer en la región del lago Nahuel Huapi en 1922, el Parque Nacional del Sud, existente en los papeles pero no en el financiamiento (Núñez y Núñez, 2012). Los autores marcan que se dio más importancia a sostener el turismo antes que la preservación, pues ubican en los ojos de los extranjeros ilustrados la capacidad de valorar el paisaje.

De esa tradición anglosajona, una de las obras que más impactó en el imaginario regional fue la de Willis "El norte de la Patagonia", publicada en $1914^{16}$. Este libro fue el resultado de un plan de desarrollo solicitado por el Ministerio de Obras Públicas. Su Ministro, Ramos Mexía, entendía que esta región sureña sería el corazón de la industrialización argentina a partir de la energía hidroeléctrica producida por los ríos del lugar (Ruffini, 2008).

Willis (1914) equiparó el potencial del desarrollo patagónico con el de Estados Unidos. En relación a los bosques nativos de la zona cordillerana, indica: "El problema de la conservación de la foresta andina abarca tres cuestiones, a saber: cómo impedir los incendios, cómo desmontar la vegetación natural con mayor ventaja y sin destruir su eficacia en la regula- 
ción de aguas, y como reemplazarla por especies de mayor valor" (pp. 11-12).

Reconoce que las industrias de la Patagonia son las ganaderas y llama la atención por la destrucción de las pasturas, culpando a las prácticas de trashumancia y reclamando la intervención estatal al asumir como problema la ignorancia de las poblaciones establecidas allí y no a la estructura productiva existente.

Willis buscó dar cuenta del potencial de la región para un desarrollo industrial, pero su mirada debió enfrentar las tensiones internas de los modelos de desarrollo estatales, en una muestra que en la jerarquía de conocimiento y construcción territorial no se forjan discursos monolíticos ni únicos, pues desde el gobierno se desestimó el modelo de desarrollo que estos intelectuales buscaron llevar adelante. El plan de Ramos Mexía y Willis desafiaba al orden económico territorial establecido en dos puntos. Por un lado, la adopción de la integración con Chile como crecimiento natural, que tensionaba discursos nacionalistas en crecimiento. Por otro, tomaba como centro del desarrollo industrial a un espacio situado en la Patagonia, en detrimento del centro histórico del país, Buenos Aires. Así, planteaba la creación de un centro económico alternativo, en un sitio remoto, que además, consideraba una fuerte articulación con el sur chileno en detrimento del vínculo con Buenos Aires. En el abierto desafío al orden establecido, el proyecto fue abandonado por el Estado argentino.

Pero más allá de esta disputa interna al país, el texto de Willis también refiere a un ordenamiento social inferido de la interpretación del paisaje. El ordenamiento viene dado de un orden económico presupuesto como preexistente. Ese orden, que es el capitalista, presenta matices en la tradición científica germana. Carreras (2011) recorre en detalle el imaginario de la Sociedad Científica Alemana instalada en Argentina, de la cual provienen la mayor parte de los naturalistas que describen la Patagonia, pues no sólo acompañaron el proceso de conquista, sino que se instituyeron en la referencia central del conocimiento geográfico nacional, en la Sociedad Argentina de Estudios Geográficos GAEA que, desde la década del '20, reunió a los más encumbrados naturalistas y antropólogos. La autora señala que, antes que el rédito económico, en la escala de valores de estos científicos, predominaba el prestigio social. "Sus integrantes eran mayoritariamente protestantes y constituían una élite cultural en la medida en que ocupaban posiciones y profesiones en instituciones capaces de transportar modelos burgueses imponiéndolos como dominantes" (Carreras, 2011, p.18). Pero no sólo se trataba que el modelo de vida burgués estaba por encima de las dinámicas de concentración de riqueza, Carreras reconoce formas diferentes de pensar la producción de conocimiento.

Si bien la ciencia se entiende en general como una forma específica de conocimiento sistemático y organizado, la tradición empirista (británica), generó definiciones relacionadas a la observación, razonamiento o erudición. Pero el hacer ciencia en Alemania tenía otras connotaciones. Es la actividad de investigación, que no es mera observación, la que produce los conocimientos. "En ese sentido, lejos de presentarse como una naturaleza contemplativa, el hombre de ciencia alemán aparece como un hombre de acción" (Carreras, 2011, p. 19). Cabe destacar que en todos los escritos, sea cual sea el origen, la actividad científica sobre Patagonia se describe como una gesta heroica. Nadie, simplemente observa, es más, John Hatcher, en una expedición publicada en 1903 desde la Universidad de Princeton, Estados Unidos ${ }^{17}$, llega a plantear que simplemente mirar la naturaleza en Patagonia limita la capacidad de raciocinio. El norteamericano señala que la mente se ve desafiada en la medida en que el razonamiento y la acción se sumen a la observación. Los pobladores nativos, o los científicos que sólo observan, devienen en sujetos de la barbarie o del desierto, en una reflexión que trae reminiscencias lamarckianas.

Carreras marca diferencias en las aproximaciones de las dos tradiciones, señalando que la identificación de la palabra "ciencia" con las disciplinas exactas y naturales es mucho más fuerte en español e inglés que en alemán, idioma en que las Humanidades son incluidas en el campo semántico de la ciencia a partir de su mismo nombre. Un ejemplo de la particular mirada alemana, extremada en cuanto la acercamos al reconocimiento del bosque, se encuentra en el escrito del botánico Max Tepp, originalmente elaborado en alemán y traducida y prologada por el Secretario General de GAEA, Edmundo Wernicke, titulada "Árboles y arbustos de la Cordillera Patagónica", publicado en $1936^{18}$. Este libro apela al fortalecimiento del sentir nacional como objetivo de la obra. Así se indica "Lástima que el lento crecimiento de los árboles indígenas los coloca en una posición inferior a los importados. Todo progreso general es cruel para el individuo. Esta reflexión volvió a mi mente al leer unos artículos del señor Máximo Tepp... la lectura... me sugirió que tam- 
bién nuestros árboles serranos probablemente desconocidos a la mayoría del público argentino, estarían condenados a... desaparición... Por buenaventura contamos con la existencia y proyectos de parques nacionales para salvación de flora y fauna. Así manifesté al autor que a mi juicio de antiguo poblador, sus artículos poseían el innegable mérito de dejar memoria justiciera de estas arboledas amenazadas a su vez. El me propuso que yo amoldara su trabajo al ambiente nacional. Por considerarlo un deber con nuestra arboleda indígena, acepté gustoso tan patriótico ofrecimiento." (Wernicke, 1936, pp. 6-7).

Esta reflexión asume una jerarquía arbórea relacionada con la velocidad de crecimiento. Esto explicita un marco economista de referencia, que se fortalece en la consideración que la única posibilidad de crecimiento económico es a partir de la destrucción de lo nativo. Los bosques, a los ojos de Wernicke, como los pueblos originarios a los ojos de tantos, están condenados a desaparecer por la propia dinámica del desarrollo natural. Sanz Lafuente (2003) reconoce este debate en el manejo forestal alemán de la segunda mitad del siglo XIX, donde la valoración moral nacionalista del bosque deviene en el argumento central para la conservación. Estos elementos reaparecen, ya en la década del '30, en el texto de Tepp.

La obra presume la ignorancia local, que aparece incapaz de valorar la flora nativa. Un aspecto que los expertos extranjeros tienen la sensibilidad de reconocer, y a la cual Wernicke refiere presentándose a sí mismo como "antiguo poblador", cruzando el nivel emotivo con la valoración científica inicial que reconoce en la obra. Así es un deber patriótico traducir una mirada alemana sobre la flora autóctona, por la incapacidad local de generar este afecto y/o conocimiento.

Ya dentro del texto de Tepp, el modo de construir lo afectivo se resolvió incorporando una adjetivación valorada por la cultura alemana, como parte de las propiedades de las plantas que se presentan. Así se indica, entre otros, "Ciprés-el triunfador", "Alerce-el majestuoso", "Palomita-la soñadora", "El maitén-el buen compañero" o "Canelo-el sacerdotal".

El título del presente artículo "Ciprés, el triunfador" es ejemplo de los textos citados como "memoria justiciera". Inmediatamente debajo del título indica "Libocedurs chilensis - Pinácea", y comienza "Escasas gentes llegan a querer la cordillera en la forma entrañable como aman el terruño do nacieron ... Más no falta quien ama la cordillera con todas sus fibras, aún donde ella se tornó ríspida y esquiva: El ciprés. Hasta allí donde no aparece ni pizca de humus, sobre las desnudas rocas isleñas del Nahuel Huapi y del Mascardi, y los roquizos declives del Traful y Limay, el ciprés no abandona el terruño, cual si dijera -ino parto de aquí salvo que Dios me ordene!" (p. 7). Sigue, dando características de la personalidad del ciprés y acciones como "cuando al planear los cóndores alrededor de la copa, el viento pasa silbando entre las alas de estas aves gigantescas, el ciprés solitario escucha cual si percibiera la música más sublime" (p. 8), humanizando todo el paisaje, en oraciones tales "como le agrada al sol reposar sobre el follaje cipresino y sentirse mimado entre sus ramas" (p. 9).

En el texto, en cada una de las denominaciones dadas a las plantas, se presenta el nombre científico de la misma y una breve descripción. En la descripción se explica el adjetivo en dos modalidades. Una, relacionada a un estereotipo de persona y la correspondiente explicación de porqué provoca simpatía, como en el caso citado del ciprés; otra, por la utilidad misma frente a la población, como aromático o dulcificante. Así, por ejemplo, respecto de "Maqui - el dulcificante", se indica "Aristotelia maqui - Eleocarpácea". "En el calafate y el maqui posee la cordillera dos frutos silvestres cuyas frutas son apetecidas en primera línea por los niños lugareños" (p. 25), y sigue una descripción sin la carga de humanidad vista en el ciprés, en línea con la mirada utilitarista "las frutitas ya pintonas, de un tinte azul obscuro, atraen a las golosas avecillas, en franca competencia con los niños aficionados a su dulce sabor. También las amas de casa aprecian el fruto del maqui, pues preparan con él una mermelada exquisita o componen un jarabe de propiedad febrífuga" (p. 25).

Es interesante que en la descripción de las plantas humanizadas se apele a modelos de personas "universales", omitiendo en el relato la larga tradición oral de los pueblos originarios, que tienen sus propias mitologías para afianzar la empatía con el entorno, e incluso relatos propios para humanizar lo vegetal. Tepp desconoce esto, Wernicke tampoco lo introduce, a pesar de citar explícitamente en términos genéricos a las poblaciones nativas en el relato, como si la universalidad de la mirada germana también los cubriera.

Recordemos que en GAEA estaban los más importantes naturalistas y antropólogos, como Carlos 
Ameghino, Francisco de Aparicio o Lehmann Nitsche, entre otros, así que no se trata de un desconocimiento sobre los pueblos originarios patagónicos, sino de reubicarlos en jerarquías ancladas en las políticas hegemónicas. En el texto el nivel de invisibilidad de las poblaciones locales es tal que las imágenes que se eligen para ilustrar las plantas nativas de la Patagonia, remiten a pueblos reconocidos en otras latitudes, como los incas, diaguitas, etc. (Figura 2)

El carácter científico de la obra está en la referencia a GAEA al principio, la introducción del nombre científico de las especies y las imágenes del final, con el dibujo erudito de cada una de las mismas, asociadas a fotos tomadas por el propio Tepp. Así, desde un discurso explícitamente anclado en órdenes morales y éticos, se introduce la mirada científica naturalista mediada por la tecnología, dando la ilusión de homogeneidad entre ambos discursos en este solapamiento. En el citado texto de Anasagasti et.al (1926) se alude al modelo norteamericano, pero se recuperan los estudios de los alemanes en cuanto a la geología, flora y fauna.

La mirada de los científicos alemanes es humanista, y de allí invisten al bosque con valores humanos desde los cuales la sociedad es juzgada, ocultada y ordenada en la clave utilitarista y la ciencia aparece como auxiliar del aparato económico que se desliza al lugar de naturaleza. Si de aquí pensamos la huma-

FIGURA 2: Imagen de "Árboles y arbustos de la Cordillera Patagónica"

Mas el destino es inmutable. Cuando en los primeros días primaverales los reverdecidos chacayes contemplan las filas de los compañeros, distinguen a más de uno que ya no responde al llamado. Los troneos sombríos y desnudos atestiguan su muerte, y por los follajes verdes de los hermanos, corre trémula emoción, en temor al próximo igual fin.

Chacay! - exclaman entonces los araucanos¡También éste!

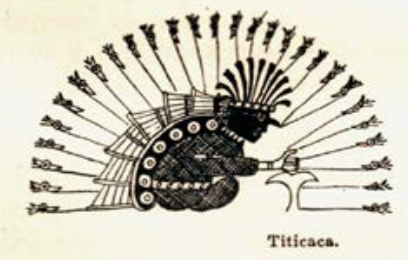

Tepp, 1936, p. 37. nidad desde la forma de considerar la salud ya vista tenemos dos elementos para sopesar. Primero, la vinculación entre salud y enfermedad, y segundo, la forma de considerar la salud de esa humanidad, ligada a la gobernabilidad.

\section{DE LA NATURALEZA IDEAL A LA SALUD SOCIAL}

Cardona Rodas (2005) ubica en un escenario latinoamericano la reflexión sobre salud y enfermedad. El autor señala que enfermedad y salud no son opuestas, pues con las correctas intervenciones lo insalubre puede tornarse saludable. Esta noción, aplicada a la apropiación y conocimiento del bosque resulta iluminadora para la comprensión de las ideas biológicas que se despliegan y su conexión con las políticas públicas que se definen.

El bosque patagónico es presentado como sanador de una sociedad enferma. Debemos recordar que la relevancia de este espacio no es menor, apelar al orden del bosque es, en estos años, apelar al orden universal. En el texto de Anasagasti et.al. (1926) los límites del Parque Nacional del Sud se reconocen referidos "...a la delimitación natural de una entidad botánica que abarca... todos los elementos fitogeográficos de importancia" (p. 286). Y continúa "Hay pocos lugares en el mundo que reúnan, en un área relativamente reducida como la de este parque, una diversidad tan grande de plantas, y raras veces el botánico encontrará como campo de estudio una región de tanta belleza como la del lago Nahuel Huapi..." (p. 287). Si a esto sumamos el organicismo como base del pensamiento político del período, observamos un punto de inflexión en el momento de armado y definición de los Parques Nacionales, donde la pregunta por lo estético es la pregunta por la intervención, y entonces volvemos a los ejes desde donde se piensa la salud social. Vallejo (2004) señala que Pende “... sumó a los cuatro biotipos la teoría de las cuatro armonías biológicas que debían perseguirse para alcanzar la eugénica perfección humana: la belleza que era la armonía de las formas; la salud que era la armonía de las funciones; la bondad que era la armonía de los sentimientos; y la sabiduría que era la armonía del intelecto". (Vallejo, 2004, pp. 229-230).

Es una metodología basada en lógicas estéticas, un punto central para reflexionar sobre las tramas discursivas que subyacen en la presentación del bosque, sobre todo, en relación a la salvedad que hace Vallejo 
(2004), al indicar que de este organicismo derivaba la fundamentación de las desigualdades sociales, un aspecto largamente recorrido en relación a la organización social de las poblaciones cordilleranas patagónicas (Núñez, 2014; Méndez y Podlubne, 2008). Vallejo (2004), citando a Pende, menciona "Del mismo modo que en la colectividad de los tejidos y de las células de un organismo existen, para la gran ley de la división del trabajo, clases celulares energéticamente diferenciadas que trabajan en armonía unas con otras en el recíproco interés, que es el interés colectivo, del mismo modo igualmente en el organismo nacional las clases de ciudadanos serán ahora antes las clases biológicas, las clases energéticamente diferenciadas de los trabajadores y productores". (p. 237).

En esta estructura de ideas, los Parques Nacionales pueden ser vistos como parte constructora de la salud social. Fortunato (2005), reconoce la institucionalización en el mismo proceso de concreción de la preservación, presentando los Parques Nacionales como invenciones políticas antes que innovaciones ecológicas. Llama la atención sobre la adjetivación "nacional", en tanto refiere a un orden político preexistente a la valoración del paisaje que se reconoce como sublime. Porque no son parques naturales o salvajes, son nacionales.

Bustillo, primer director de la Dirección de Parques Nacionales creada en 1934 y principal gestor de una estructura concreta de conservación que toma como foco de actividades el recientemente creado Parque Nacional Nahuel Huapi, apela a elementos trascendentales que confunden lo patriótico con la conservación. Así, en $1946^{19}$ reconocía en la frontera patagónica, la amenaza de la invasión, y en el bosque la estética de la esencia nacional desde la que se consolidaban la conciencia ciudadana, indicando “... para mantener despierto y alerta el espíritu argentino, para eso y nada más que para eso, Dios ha colocado entre los peligros de la frontera las grandes bellezas de nuestra tierra" (p. 26).

En las décadas del '20 y '30 la preservación planteaba equilibrios fijos en lo intocado, de modo que la planificación para promocionar cambios involucraba la sociedad antes que el entorno, y allí la pregunta por la salud cobra relevancia. Pues pensar que la política de la preservación se liga al imaginario de "salud social" propia del período nos lleva directamente a los supuestos (racistas y sexistas) ligados a la salud ambiental descripta desde la teoría de Pende, que se reconocen en Argentina (Vallejo, 2004).

De aquí, en función de los modos de conocer, y a partir de las consideraciones sobre la salud social, podemos armar un cuadro de doble entrada que sintetice los representantes y las políticas y perspectivas de las décadas del '20 y ' 30 .

Cuadro 1: Sistema de creencias proyectadas en el bosque y población patagónicos

\begin{tabular}{|c|c|c|c|c|}
\hline \multirow[b]{2}{*}{ Eugenismo } & \multicolumn{4}{|c|}{ Utilitarismo } \\
\hline & Norteamericano & Representantes & Alemán & Representantes \\
\hline $\begin{array}{l}\text { Lombrosiano. El } \\
\text { control desde el } \\
\text { cuerpo. Lamarckismo. } \\
\text { Influencia ambiental } \\
\text { en la evolución }\end{array}$ & $\begin{array}{l}\text { Cambio de especies. } \\
\text { El bosque como } \\
\text { resguardo de la } \\
\text { cuenca. Poblamiento } \\
\text { turístico en Bariloche. } \\
\text { Poblamiento agrícola } \\
\text { e industrial en la } \\
\text { región aledaña }\end{array}$ & $\begin{array}{l}\text { Theodore Roosevelt, } \\
\text { Bailey Willis, John } \\
\text { Hatcher, Horacio } \\
\text { Anasagasti }\end{array}$ & $\begin{array}{l}\text { La riqueza de las } \\
\text { especies y el espíritu } \\
\text { del bosque }\end{array}$ & $\begin{array}{l}\text { Hermann Burmeister, } \\
\text { Ricardo Napp, Pablo } \\
\text { Günther Lorentz, } \\
\text { Gustavo Niederlein, } \\
\text { Adolfo Döring, } \\
\text { Federico Schulz }\end{array}$ \\
\hline $\begin{array}{l}\text { Nicola Pende. El } \\
\text { control desde los } \\
\text { diferentes niveles de } \\
\text { belleza, la } \\
\text { anormalidad invisible }\end{array}$ & $\begin{array}{l}\text { El armado de los } \\
\text { Parques Nacionales } \\
\text { como estructura de } \\
\text { frontera. La montaña } \\
\text { como marca de } \\
\text { diferencia o } \\
\text { vinculación (apelativo } \\
\text { a la geografía física). } \\
\text { Intervenciones y } \\
\text { cambios en la propia } \\
\text { estructura del bosque }\end{array}$ & $\begin{array}{l}\text { Exequiel Bustillo, José } \\
\text { María Sarobe, José } \\
\text { María Moldes }^{20}\end{array}$ & $\begin{array}{l}\text { Se plantea el espíritu } \\
\text { humano reflejado en } \\
\text { lo forestal. Lo forestal } \\
\text { como límite de las } \\
\text { miserias humanas. } \\
\text { Lo forestal como } \\
\text { muestra del deber- } \\
\text { ser. El bosque } \\
\text { disciplinador. } \\
\text { El paisaje y el clima } \\
\text { como referencia }\end{array}$ & $\begin{array}{l}\text { GAEA, Federico } \\
\text { Reicher, Pablo } \\
\text { Groeber, Anselmo } \\
\text { Windhausen, Carl } \\
\text { Curt Hosseus, } \\
\text { Edmundo Wernicke, } \\
\text { Walter Knoche, Max } \\
\text { Tepp }\end{array}$ \\
\hline
\end{tabular}


Es interesante que los científicos se reconozcan en una de las tradiciones -la germana- y los gestores, técnicos y políticos en la otra -anglosajona, pero que sin embargo en sus escritos encontremos cruces permanentes que muestran cómo ambas perspectivas resultan funcionales en el particular control y significado que se busca establecer en la región.

\section{REFLEXIONES FINALES}

Uno de los elementos a destacar es que el reconocer tradiciones diferentes no significa que encontremos perspectivas antagónicas o alternativas, sino que, por lo que vemos, se alimentan mutuamente en el diálogo que permite ocultar el origen último del argumento disciplinador. Una naturaleza, que es argumento económico y moral, permite pensar que esos órdenes se inscriben tan fijos como la naturaleza que se presupone. Lo global, en sentido de orden hegemónico del mundo, deviene en lo más profundamente local, como la mirada del ciprés sobre sí mismo, concebible desde el romanticismo naturalista alemán, pero presentado como parte del argumento patriótico-capitalista que hace al pueblo entender como argentino y valioso a estos especímenes. En este proceso se eclipsa la inscripción global-local de la comprensión del entorno y de las poblaciones del mismo. Es difícil encontrar una obra que explicite tanto esta operación como "Árboles y arbustos de la cordillera patagónica", desde la misma no sólo el utilitarismo, que en sí es notable en cuanto estudio

\section{NOTAS}

1. La política de creación se inicia en 1903 , se legisla por primera vez en 1922, con la creación del Parque Nacional del Sud en el mismo espacio que el actual Parque $\mathrm{Na}$ cional Nahuel Huapi, pero se establece efectivamente como política nacional, en 1934, con la creación de los parques nacionales Nahuel Huapi e Iguazú (Vejsbjerg et al., 2014).

2. Napp, Ricardo (1876) La república Argentina. Buenos Aires: Sociedad Anónima.

3. El debate entre Argentina y Chile acerca del criterio de delimitación de los límites de sur se desarrolla y resuelve por vías diplomáticas, y se prolonga hasta 1902, allí se firman los acuerdos que aún rigen en el espacio.

4. Melchert, Federico (1876) Indios y Fronteras. En Napp La República Argentina. Buenos Aires: Sociedad Anónima: 399-411. científico tomemos, sino el comportamiento moral privado deviene en resultante de la producción de conocimiento. La salud pública, inscripta en el eugenismo latinoamericano, encuentra en el bosque un reflejo y un medio para consolidar la sanidad social.

El conocimiento de lo biológico fluctúa entre el conocimiento del paisaje y el de la salud. A lo largo de esta exposición buscamos mostrar cómo el reconocimiento del bosque pasó por convertirlo, en las décadas del '20 y '30 en sujeto $-y$ no objeto-político. Es decir, en reconocerle agencia, intención, sentido y utilidad en una escala mayor a sí mismo. Esto, que parecería superar la dicotomía sociedad naturaleza, en tanto un objeto de la naturaleza deviene en sujeto de derecho (preservación), no es así. En la llamativa construcción de conocimiento se puede observar como esto, antes que superar, profundiza la dicotomía sociedad-naturaleza, en tanto esa naturaleza humanizada en clave de desigualdad social es referencia de jerarquía social, silenciando las voces subalternizadas desde la apropiación militar del espacio, deshumanizando la humanidad y estereotipando un paisaje permanentemente ajeno a la sociedad inmediata.

\section{AGRADECIMIENTOS}

Agradecemos los comentarios de los revisores anónimos, cuyos aportes mejoraron la propuesta original. Este artículo es parte de los proyectos DIULA N12/16 "Acceso restringido: Paisaje, poder y política en los Andes Norpatagónicos" ULagos, Osorno.

5. Estanislao Zeballos, intelectual, político y jurisconsulto. Fundador de la Sociedad Científica Argentina (1872) y del Instituto Geográfico Argentino (1879).

6. Zeballos, Estanislao (1878) La conquista de quince mil leguas: estudio sobre la traslación de la Frontera Sud de la República al Rio Negro, dedicado á los gefes y oficales del ejército expedicionario. Buenos Aires, E.P. Coni.

7. Lorentz, Pablo (1876) "Cuadro de la vegetación de la República Argentina". En Napp La república Argentina. Buenos Aires, Sociedad Anónima, pp. 77-136.

8. El error de Zeballos es pasado por alto por el grupo científico que acompaña la "Conquista del Desierto". En Doering, Adolfo; Berg, Carlos y Holmberg Eduardo (1881) Informe oficial de la Comisión Científica agregada al Estado Mayor General de la expedición al Rio Negro. Zoología. Buenos Aires, Imprenta Ostwald y Martínez, se lo cita como “Una muy buena recopilación y resumen general sobre los 
acontecimientos previos á la espedicion del General ROCA al Rio Negro" (p.4).

9. Moreno, Francisco (1902) La Frontera Chileno-Argentina. Buenos Aires, Imprenta Nacional. Para ver un detalle de esta controversia, consultar Sagredo Baeza (2016).

10. Moreno, Francisco (1879) Viaje a la Patagonia Austral 1876-1877. Buenos Aires, Imprenta de La Nación. Si bien esta es una de las obras más conocidas de Moreno, este no es su primer derrotero por el sur. En 1873 realizó su primera excursión a Tandil, Azul, Carmen de Patagones y Valle del Rio Negro de la que resultará una de sus primeras publicaciones arqueológicas en el primer número de los Anales Científicos Argentinos. En 1874 viaja a la bahía de Santa Cruz para "explorar las tierras donde se habían establecido 'algunos chilenos'" y llegar a la naciente del río Santa Cruz (no se logra). En 1875 realizó salidas cortas a Punta Alta, Olavarría y Azul, enviando una descripción al Congreso de Antropología y Arqueología Prehistórica de Estocolmo. Finalmente, en 1875-6 viaja al Nahuel Huapi con el apoyo de Mitre, Zeballos y la Sociedad Científica Argentina. Este viaje fue publicado como "Viaje a la Patagonia septentrional" en los Anales de la Sociedad Científica Argentina 1:182-197. Finalmente, en1876-77 completa el frustrado viaje a las nacientes del río Santa Cruz que publicará en la mencionada obra de 1879

11. Cabe mencionar que la Comisión Científica de 1879 es especialmente crítica respecto de las descripciones realizadas por Moreno, a quien le reconocen aportes en el campo de la antropología, pero grandes descuidos en zoología, botánica y geología.

12. Por ejemplo, hasta 1958 en la Patagonia continental argentina no se pudo elegir autoridades propias o tener representantes en las cámaras legislativas nacionales. En Tierra del Fuego esto se extendió hasta 1992.

\section{BIBLIOGRAFÍA}

Bandieri, Susana (2015), "La Patagonia en clave regional: un camino posible para una historiografía renovada". Folia Histórica del Nordeste, (24), pp. 15-41.

Bessera, Eduardo (2008), "Políticas de Estado en la Norpatagonia Andina. Parques Nacionales, desarrollo turístico y consolidación de la frontera. El caso de San Carlos de Bariloche (1934-1955)". Tesis de Lic. En Historia. Universidad Nacional del Comahue.

Boyer, Christopher (2015), Political landscapes. Forests, Conservation, and Community in México. Durham: Duke University Press.

Cardona Rodas, Hilderman (2005), "Theatrum Monstruosum: El lenguaje de lo difuso en el saber clínico colombiano de finales del siglo XIX y comienzos del XX". Co-herencia 2(3), pp. 151-174.

Carreras, Sandra (2011), "Los científicos alemanes en la Argentina: identidades y formas de organización". En: Chicote,
13. Clements, Frederic (1916), Plant Succession. Washington. Clements, Frederic (1936) "Nature and structure of the climax". The journal of ecology 24, pp. 252 -284.

14. Nicola Pende, médico italiano, pro-eugenésico y fundador de la 'biotipología' italiana.

15. Anasagasti Horacio; Windhausen, A. Hosseus, C. Frey, Emilio (1926) "El parque Nacional del sud. Rasgos de la geografía física, de la historia y del porvenir de la región del lago Nahuel Huapi". Anales GAEA II (2), pp. 264-316.

16. Willis, Bailey (1914) El Norte de la Patagonia. Naturaleza y riquezas. Estudio de los elementos del tráfico del ferrocarril nacional de fomento desde Puerto San Antonio hasta el lago Nahuel Huapi y sus ramales dentro de la cordillera hasta su extensión internacional con término en Valdivia en Chile. New York, Scribner Press.

17. Hatcher, John (1903), Reports of the Princeton University Expeditions to Patagonia, 1869-1899. USA, Princeton University.

18. Tepp, Max (1936), Árboles y Arbustos de la Cordillera Patagónica. Buenos Aires, El Umbral Argentino y Wernicke, Edmundo (1936) "Advertencia". En Tepp Árboles y Arbustos de la Cordillera Patagónica. Buenos Aires, El Umbral Argentino, pp. 6-7. Un antecedente a esta obra es el texto de Alfredo Kölliker, Franz Kühn, Fritz Reichert, Adolfo Tomsen y Lutz Witte, Patagonia. Resultado de las expediciones en 1910 a 1916, editado por la Sociedad Científica Alemana en 1917.

19. Bustillo, Exequiel (1946) Parques Nacionales. Buenos Aires, Guillermo Kraft Ltada.

20. Moldes, José (1937) La tierra de los Tehuelches, Buenos Aires, Lito y Sarobe, José (1935) La Patagonia y sus problemas. Buenos Aires, Aniceto López, son obras premiadas por distintos grupos de académicos de la década del '30 y fueron reconocidas como síntesis de la mirada sobre el territorio en su época.

Gloria y Göbel, Bárbara (eds.), Ideas viajeras y sus objetos: El intercambio científico entre Alemania y América austral. Madrid: Iberoamericana/Vervuert, pp. 17-28.

Carrizo, Gabriel (2007), Saldando deudas. El peronismo en la gobernación militar de Comodoro Rivadavia, 1944-1955. Córdoba: UNC.

Coronato, Fernando (2010), "El rol de la ganadería ovina en la construcción del territorio de la Patagonia". Tesis doctoral. Escuela Doctoral ABIES, Paris TECH.

Daston, Lorraine y Vidal, Fernando (2004), The moral authority of Nature. Chicago: The University Of Chicago Press.

Deléage, Jean-Paul (1993), Historia de la ecología. Uruguay, Nordan Comunidad.

Diegues, Carlos (2005), El mito moderno de la naturaleza intocada. Brasil: Center for Research on Human Population and Wetlands. 
Fortunato, Norberto (2005), "El territorio y sus representaciones como fuente de recursos turísticos. Valores fundacionales del concepto de "parque nacional". Estudios y Perspectivas en Turismo, 14 (4), pp. 314-348.

Fritz-Vietta, Nadine (2016), "What can forest values tell us about human well-being? Insights from two biosphere reserves in Madagascar". Landscape and Urban Planning 147, pp. 28-37.

Horta Duarte, Regina (2010) A biologia militante: O Museo Nacional, especializacao cientifica, divulgacao do conhecimento e practicas politicas no Brasil, 1920-1945. Belo Horizonte: Editora UFMG.

Horta Duarte, Regina (2014), "Zoogeografia do Brasil: Fronteiras nacionais, percursos pan-americanos". Latin American Research Review, Vol. 49, No. 2, pp. 68-83.

Iuorno, Graciela y Edda Crespo (Coord.) (2008), Nuevos Espacios, Nuevos Problemas. Los Territorios Nacionales. Neuquén, UNPa-UNCo.

Klubock, Tomas (2014), La Frontera: Forests and ecological conflict in Chile's Frontier territory. Durham, Duke University Press.

Lois, Carla (2006), "Técnica, política y "deseo territorial" en la cartografía oficial de la argentina (18521941)". Scripta Nova. Vol. X, núm. 218 (52). Disponible en http://www. raco.cat/index.php/ScriptaNova/article/view/58255 [consultado 02/03/2017]

Martínez Alier, Juan (1993), "Temas de historia económica-ecológica". AYER. Historia y Ecología 11, pp. 19-48.

Méndez, Laura y Muñoz, Jorge (2013), "Alianzas sectoriales en clave regional. La Norpatagonia argentino-chilena entre 1895 y 1920". Nicoletti, María y Núñez, Paula (comp.) Araucanía- Norpatagonia: la territorialidad en debate. Bariloche, IIDYPCA, pp. 152-167.

Méndez, Laura y Podlubne, Adriana (2008), “Atraer para Educar Recreando. El Proyecto Ayekan Ruca en San Carlos de Bariloche. 1934-1955". 3 Jornadas de Historia de la Patagonia. Bariloche.

Navarro Floria, Pedro (2004), Patagonia. Ciencia y conquista. Neuquén: CEP - UNComa.

Navarro Floria, Pedro (2007), "La Comisión del Paralelo 41을 (1911-1914). Las condiciones y los límites del "progreso" liberal en los Territorios Nacionales". En: Navarro, Pedro (coord.), Paisajes del progreso. La resignificación de la Patagonia Norte, 1880-1916. Neuquén, UNCo, pp. 235-296.

Nouaeillez, Gabriela (1999), "Patagonia as a Borderland: Nature, Culture and the idea of State". Journal of Latin American Cultural Studies, 8(1), pp. 35-49.

Núñez, Paula (2014), “Nación, paisajes y mujeres. Entre la metáfora, el desarrollo y el territorio", Revista Nomadías 18, pp. 179-201.

Núñez, Paula (2015), "The peronist incomplete reconstruction of the border: An analysis of the Nahuel Huapi region, Ar- gentina (1946-1955)". Estudios fronterizos, 16 (31), pp. 56-73.

Núñez, Paula y Núñez, Martín (2012), “Conocer y construir naturaleza en el sur argentino". En: Silva, Cibelle Celestino y Salvatico, Luis (eds.), Filosofia e Histórica da Ciencia no Cone Sul. Selecao de trabalhos do $7^{\circ}$ Encontro da AFHIC. Porto Alegre, [ntr]mentes editorial, pp. 428-437.

Ruffini, Marta (2008), "La Patagonia en el pensamiento y la acción de un reformista liberal: Ezequiel Ramos Mexia (1852-1935)". Quinto Sol, 12, pp. 127-150

Sagredo Baeza, Rafael (2016), "Territorio y saber en disputa. La controversia limítrofe chileno argentina sobre los Andes", Asclepio, 68 (2): p152. doi: http://dx.doi.org/10.3989/ asclepio.2016.24.

Sanz Lafuente, Gloria (2003), “Naturaleza y ciencia forestales en Alemania. Aproximaciones a la historia de una tradición académica". Cuadernos de la Sociedad Española de Ciencias Forestales, 16, pp. 161-166

Schiebinger, Londa (2004), "Human Experimentation in the Eighteenth Century: Natural Boundaries and Valid Testing". En: Daston, Lorraine y Vidal, Fernando (eds.), The moral authority of Nature. Chicago: The University of Chicago Press, pp. 384-408.

Travers, Henry; Winney, Kyle; Clements, Tom; Evans, Tom; Milner-Gulland, E.J. (2015), "A tale of two villages: An investigation of conservation-driven land tenure reform in a Cambodian Protection Forest". Land Use Policy 43, pp. 186-196.

Vallejo, Gustavo (2004), “El ojo del poder en el espacio del saber: los institutos de biotipología". Asclepio, I (VI), pp. 219-244.

Vallejo, Gustavo; Miranda, Marisa (2004), "Evolución y Revolución: explicaciones biológicas y utopías sociales". En: Biagini, Hugo y Roig, Arturo (dir.), El pensamiento alternativo en la Argentina del siglo XX: identidad, utopía, integración (1900-1930).Buenos Aires, Biblos, pp. 403-418.

Vallejo, Gustavo; Miranda, Marisa (2014), "Iglesia católica y eugenesia latina: un constructo teórico para el control social (Argentina, 1924-1958)", Asclepio, 66 (2): p055. doi: http:// dx.doi.org/10.3989/asclepio.2014.19.

Vejsbjerg, Laila; Núñez, Paula; Matossian, Brenda (2014), "Transformation of Frontier National Parks into Tourism Sites. The North Andean Patagonia Experience (19341955)". Almatourism, 5(10). Disponible en https://almatourism.unibo.it/article/viewFile/4769/4260 [Consultado 14/05/2016].

Werry, Margaret (2008), "Tourism, race and the state of nature". Cultural Studies, 22, 3: 391- 411.

Zusman, Perla (2012), “Panamericanismo e imperialismo no formal: Argentina y las exposiciones universales estadounidenses de Búfalo (1901) y San Francisco (1915)". Scripta Nova, XVI. Disponible en http://www.ub.edu/geocrit/sn/ sn-418/sn-418-64.htm [Consultado 14/05/2016]. 